\title{
Dentistry during COVID-19: patients' knowledge and satisfaction toward health protocols COVID-19 during dental treatment
}

Parvin Parvaie ${ }^{1}$ and Freshteh Osmani ${ }^{1,2^{*}}$ (D)

\begin{abstract}
Background: Coronavirus disease 2019 (COVID-19) as an infectious disease primarily spreading through droplet infection in dental treatment. Patient satisfaction is an indicator of healthcare quality service. Quality of healthcare service and patient satisfaction has been affected by the COVID-19 pandemic. This study aims to assess the knowledge and satisfaction toward health protocols COVID-19 during dental treatment among dental patients.

Methods: An institutional-based cross-sectional study was conducted on 270 dental patients using a self-designed questionnaire consisting of knowledge and satisfaction about health protocols COVID-19 during dental treatment through a random sampling technique. Data were imported to SPSS version 21 for analysis. Descriptive and analytical statistics were used to identify the factors associated with their knowledge and satisfaction. A $p$ value $<0.05$ was considered statistical significance.
\end{abstract}

Results: Totally, 270 dental patients with mean age of $37.6 \pm 6.7$ years participated in the study. The mean knowledge score was $36.7 \pm 3.5$, as considerable number of participants were unaware about the risk associated with dental treatment as well as restrictions imposed on dental procedures. About 18\% of participants experienced one or other form of dental complaints during the lockdown period. The overall level of patient satisfaction was $44.6 \%$.

Conclusion: It can be concluded that, public knowledge is to be improved about risk of virus transmission that can be related with dental treatment and also people should be encouraged to use virtual facilities, such as teledentistry, so that no dental emergencies is left untreated during the pandemic time. In addition, the level of satisfaction was in a medium level for dental patients in the study area. Specifically, we deduced from the results that social/physical distancing measures are one of the mechanisms to decrease the fear of exposure to the COVID-19.

Keywords: Patient satisfaction, COVID-19, Knowledge, Dentistry

\section{Introduction}

Outbreak of COVID-19 began in December 2019 [1, 2]. This virus has spread in the whole world until now. The virus can spread through respiratory droplets, via the mucous membrane of the mouth, nose, and eyes $[3,4]$. Using handpieces and ultrasonic instruments during

*Correspondence: fereshteh.osmani@gmail.com

${ }^{2}$ Infectious Disease Research Center, Birjand University of Medical Sciences, Birjand, Iran

Full list of author information is available at the end of the article dental procedures leads to the generation of blood and saliva droplets. As a result, these droplets can contaminate the dental instruments and subsequently the surrounding environment. Therefore, both dental practitioners and dental patients could be at risk of being infected [5, 6]. In this way, different studies remarked that dental clinics might be a possible contagion source of viruses. These viruses can be transmitted to the patients and also the practitioner during dental practice. In a dental setting, the risk of acquiring infection from the microdroplets of an infected patient is high, because the dentist 
and their equipment are in close vicinity to the patient $[1$, 7]. The COVID-19 outbreak threatens public health in the world. Its transmissibility is higher than other similar respiratory diseases [8]. To control the spread of COVID19 , there have been adopted some protocols in Iran.

These protocols consist of closing public places, especially dental offices and dental faculties. There is always the worry of experiencing a resurgence in transmission. So that, perhaps, hospitals and clinics are facilitating the transmission of the virus to uninfected patients $[9,10]$. The diffusion of aerosol during dental operations puts them at a higher risk of getting infected [11]. Therefore, in some countries, optional dental procedures and oral surgeries have been suspended.

Due to the unique characteristics of dental treatments, standard protective measures in daily clinical practice are not effective enough to prevent the spread of COVID-19. Especially, when patients are in the latent stage of COVID-19 disease and are not aware of their infection or they hide their infection. Therefore, following the principles and health protocols in dental services during the corona epidemic is felt to be more necessary $[12,13]$. In addition, measuring the level of awareness of patients referring to the dental clinic to promote the level of awareness of the observance of health instructions in dental service centers is very important. On the other hand, in terms of clinically, evaluating the satisfaction of patients regarding healthcare services is important [14]. In return, the effect of COVID-19 has been reducing procedure and treatment adherence, increase treatment dissatisfaction, and discontinue their treatment follow-up. Since the dental faculties are open based on the decisions made in Iran [15].

Therefore, considering the stated issues and the special importance of observing health protocols to maintain the health of patients and the dental community, this study was aimed to investigate two aspects of awareness and patient satisfaction with the observance of health protocols and instructions related to COVID-19 in the environment of the dental clinic.

\section{Materials and methods Study design}

An institutional-based cross-sectional study was conducted from June 10 to 25,2020 , among Iranian dental patients referred to the dental clinic of Birjand city.

The inclusion criteria for this study was having the consent to participate in the study. Questionnaires completed with incomplete information also be excluded from the study.

The referring patients completed the determined questionnaires only if they had consent and preferably one person from each family and for the children, one of the parents answered the questionnaires. In addition, all the explanations about the questionnaires were given to the participants. Finally, after collecting the required questionnaires, all the extracted information was entered into the Spss software, then the data reviewed by the relevant expert for analysis.

\section{Sample size}

The sampling method in this study was easy sampling. According to the sample size formula, a total of 246 samples were obtained, which was considered for this study with a $10 \%$ drop in 270 samples. In this research, all patients referred to Birjand dental clinics were examined in the period from the beginning of the study until reaching the required sample size (270).

\section{Questionnaire}

This study was based on a researcher-made questionnaire. In the first stage of implementation of this study, the questionnaire designed and its validation and reliability were evaluated. One questionnaire was prepared to assess patients' awareness of familiarity with health protocols in dental clinics according to the protocols set by the Ministry of Health in dental clinics with the aim of how many the referring people are aware of the observance of these health instructions and to what extent they observe.

Another questionnaire was designed to measure patients' satisfaction with the observance of health protocols in dental clinics according to the Ministry of Health instructions that adjusted by the researcher.

This questionnaire set the principles of satisfaction from the patients' point of view to the principles set by the Ministry of Health. After adjustment, the questionnaires were evaluated for validity and reliability. Questionnaires were provided to 7 experts in the dentistry field to assess its validity. The validity of the questionnaire was calculated using the content validity method. Cronbach's alpha method was also used to measure reliability.

The questionnaire was divided into 3 sections and had a total of 52 questions. The 1st part includes sociodemographic and background information (age, sex, educational level, the continent of residence, and so on), whereas the 2nd, 3rd sections consist of questions to assess the knowledge (23 questions) including three Likert-scale items and satisfaction (17 questions) including five Likert-scale items scored from 1 to 5 $(1=$ strongly disagree, $2=$ disagree, $3=$ neutral, $4=$ agree, and $5=$ strongly agree), of dental patients about COVID19 health protocols in dentistry, respectively. To calculate the reliability of the questionnaire, a pilot study was done on 30 participants and its Cronbach's alpha 
$(\alpha)$ was obtained to be 0.78 . In addition, the incomplete responses were excluded from the main analysis.

\section{Statistical analysis}

After data collection, they were checked for completeness and coded, cleaned, and then were entered into Spss software version 21 . They were analyzed using a $t$ test. The Chi-square test or Fisher's exact test also be used to determine the relationships between kinds of variables. All studied variables are first presented using descriptive statistics in terms of data distribution and dispersion. The significance level of the tests was considered less than 0.05 .

\section{Results}

A total of 270 dental patients participated in the study and filled the questionnaire with a response rate of $98.6 \%$. Overall, among all the participants, 114 (48\%) were male, $126(52 \%)$ were female, and more than half of the participants $(n=150,62 \%)$ were between 24 and 35 years and $(42.8 \%)$ of the respondents were aged more than 45 years. The majority of the study participants were undergraduates or had a secondary school education 174 (64.7\% both). The remainder of the participants had completed primary school, middle school, or had a postgraduate degree $29,26,14$ (10.8\%, 9.8\%, 5.3, respectively). Only 25 (9.4\%) participants were illiterate. Among the participants, 122 (45\%) were married, and 148 (55\%) were single (Table 1).

Among all the participants, statements showed that their waiting time as following: less than 15 min: (100 (39.8\%)); 15-29 min: (71 (28.3\%)); 30-44 min: (41 (16.3\%)) and $>45$ min: (39 (15.5\%)) (Fig. 1). Regarding correct knowledge about the incubation period of the virus, $43.9 \%$ (118) answered this correctly (2-14 days), $44.6 \%$ (120) selected $7-14$ days, $7.4 \%$ (20) selected $7-21$ days, and $4.1 \%$ (12) selected $2-7$ days.

\section{Patients' knowledge of protective measures and health protocols towards COVID-19 in a dentistry clinic}

Knowledge of situations and symptoms that should be considered to identify patients at risk of acquiring the virus, and infection control measures in the dental environment against COVID-19 are summarized in Table 2 .

\section{Knowledge score}

The range of knowledge score was between 0 to 46 . The mean \pm SD of the total knowledge score was $36.7 \pm 3.5$. Knowledge on familiarity with health instructions of COVID-19 in the dental environment consisted of 8 questions with a mean $\pm S D$ of $9.7 \pm 1.7$. Knowledge regarding protective measures against corona
Table 1 Sociodemographic characteristics of study participants

\begin{tabular}{|c|c|c|}
\hline Variables & $\begin{array}{l}\text { Number of } \\
\text { participants }\end{array}$ & Percent (\%) \\
\hline \multicolumn{3}{|l|}{ Sex } \\
\hline Male & 144 & 52.4 \\
\hline Female & 126 & 47.6 \\
\hline \multicolumn{3}{|l|}{ Age } \\
\hline $15-24$ & 24 & 8.8 \\
\hline $25-34$ & 64 & 23.7 \\
\hline $35-44$ & 67 & 24.8 \\
\hline$>45$ & 115 & 42.7 \\
\hline \multicolumn{3}{|l|}{ Residence } \\
\hline Urban & 133 & 49.3 \\
\hline Rural & 137 & 50.7 \\
\hline \multicolumn{3}{|l|}{ Level of education } \\
\hline Primary school & 91 & 22.2 \\
\hline Diploma & 212 & 51.7 \\
\hline Bachelor & 46 & 11.2 \\
\hline Above Bachelor & 61 & 14.9 \\
\hline \multicolumn{3}{|l|}{ Marital status } \\
\hline Married & 209 & 77.3 \\
\hline Single & 61 & 22.7 \\
\hline \multicolumn{3}{|l|}{ Family members } \\
\hline$\leq 5$ & 204 & 75.8 \\
\hline$>5$ & 66 & 24.2 \\
\hline \multicolumn{3}{|l|}{ Occupational status } \\
\hline Labor & 82 & 30.5 \\
\hline Government employee & 67 & 24.6 \\
\hline Private employee & 53 & 19.5 \\
\hline Housewife & 44 & 16.4 \\
\hline Student & 13 & 4.9 \\
\hline Other & 11 & 4.1 \\
\hline \multicolumn{3}{|l|}{ Family monthly income } \\
\hline$\leq 30 \mathrm{mRial}$ & 79 & 29.4 \\
\hline 30mRial-50mRials & 69 & 25.4 \\
\hline 50mRial-70mRials & 100 & 37.0 \\
\hline$\geq 70 \mathrm{mRials}^{\mathrm{a}}$ & 22 & 8.2 \\
\hline
\end{tabular}

${ }^{a}$ Million Rials

in the dental environment had 10 questions and its mean \pm SD score was $12.87 \pm 2.8$. In addition, knowledge on the type of dental treatments allowed during the corona epidemic had 5 questions and its mean $\pm S D$ score was $6.27 \pm 0.9$

The results of this section of the study indicated that $42.4 \%$ of dental patients had good knowledge regarding protective measures and health protocols against COVID-19. Although, a significant percentage were unaware of the risk as well as restrictions associated with measures of dental treatment during the pandemic (Fig. 2). 


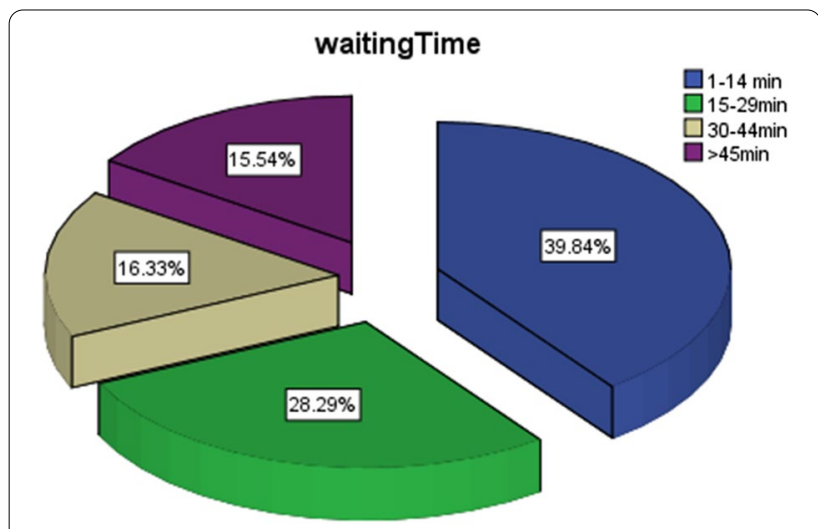

Fig. 1 Waiting time to get services and results for participants patients $(n=270)$
There was no significant difference in their knowledge scores between sex, age groups, and categories of occupation. $(P<0.05)$ (Table 3$)$.

\section{Satisfaction with the implementation of health measures and protocols regarding COVID-19 in the dental environment}

Overall, among all of the respondents, 229 (85\%) have noticed the availability of hand sanitizer at the dental clinic entrance and disinfect their hands before entry to the clinic. Almost one-third of participants have maintained physical distance at registration and waiting areas. Regarding wearing gloves, masks, and face shields, they have reported $96.5 \%$ and $86.5 \%$ of dentists wearing gloves with masks and face shields, respectively, while providing

Table 2 Correct answers of participants on designed Knowledge questionnaire

\begin{tabular}{|c|c|c|}
\hline $\begin{array}{l}\text { Question } \\
\text { number }\end{array}$ & Knowledge on COVID-19 & Correct answer (\%) \\
\hline 1 & It is mandatory to use mouthwash before providing dental services & $263(97.6)$ \\
\hline 2 & $\begin{array}{l}\text { During the corona epidemic, all dental services (emergency and non-emergency) should be provided in medical } \\
\text { centers }\end{array}$ & $229(84.8)$ \\
\hline 3 & The use of a sterile disposable package is required to provide all medical services for each patient & $226(83.6)$ \\
\hline \multirow[t]{2}{*}{4} & The screening form should be completed by the clients in the clinic & $220(81.4)$ \\
\hline & There is nothing wrong with consuming food in the dental environment & \\
\hline 5 & It is essential to have a companion in the waiting area of the clinic & $221(82.0)$ \\
\hline 6 & Bringing personal belongings to medical wards is allowed & $233(86.3)$ \\
\hline 7 & $\begin{array}{l}\text { Strong and proper ventilation is required in all areas of the clinic medical center (including a reception hall, waiting } \\
\text { area, and treatment department) }\end{array}$ & $188(69.7)$ \\
\hline 8 & The presence of alcohol disinfection gels is necessary to disinfect the hands & $252(93.4)$ \\
\hline 9 & Only the use of a protective mask with a filter mask is sufficient for all medical staff of the clinic & $196(72.5)$ \\
\hline 10 & $\begin{array}{l}\text { The use of masks, shields, disposable guns, sleeves, hats, and shoe covers is mandatory for all medical staff of the } \\
\text { clinic }\end{array}$ & $223(82.7)$ \\
\hline 11 & The use of a three-layer mask is mandatory for patients when receiving medical services and attending the clinic & $152(56.2)$ \\
\hline 12 & Mask and shield coverage is mandatory for the dentist and her/his assistant & $228(84.7)$ \\
\hline 13 & The use of an N95 mask is mandatory for patients while receiving medical services & $244(90.3)$ \\
\hline 14 & Only emergency dental treatments should be performed during this pandemic & $188(69.7)$ \\
\hline 15 & Non-emergency dental treatment is essential during this pandemic & $154(57.2)$ \\
\hline 16 & $\begin{array}{l}\text { Emergency dental services include toothache, progressive infection control, and control of patients' bleeding, as well } \\
\text { as cases that could potentially pose a risk to the patient's health if left untreated }\end{array}$ & $195(72.3)$ \\
\hline 17 & Covid 19 is transmitted through respiratory droplets & $234(86.7)$ \\
\hline 18 & If the hands are contaminated, the use of an alcoholic disinfectant is sufficient & $185(68.6)$ \\
\hline 19 & Rinsing your mouth before treatment is the most effective way to protect your corona & $212(78.5)$ \\
\hline 20 & Having a shield during the examination is essential for the dentist and assistant & $156(57.7)$ \\
\hline 21 & Having an N95 mask is essential for the dentist and assistant during the examination & $246(91.3)$ \\
\hline 22 & Do you know what the right personal protective equipment is? & $169(62.8)$ \\
\hline 23 & Hand hygiene is no longer required if personal protective equipment is used & $156(57.9)$ \\
\hline 24 & The use of shields (facial protection) is mandatory for the patient when receiving treatment & $238(88.3)$ \\
\hline 25 & The patient must use a filter mask when receiving dental services & $254(94.2)$ \\
\hline 26 & Close contact with an infected person is the most important risk factor for the disease & $214(79.6)$ \\
\hline 27 & $\begin{array}{l}\text { Treatments that lead to the production of fine droplets, the use of an N95 mask is mandatory for dentists and assis- } \\
\text { tants }\end{array}$ & $220(81.7)$ \\
\hline
\end{tabular}




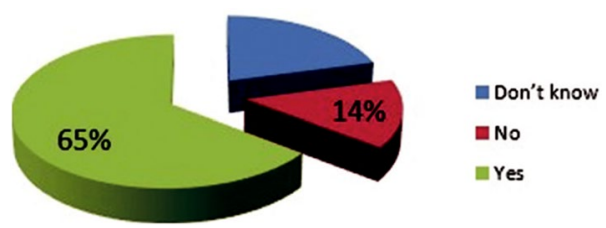

Fig. 2 Distribution of patient's knowledge about protective measures and health protocols towards COVID-19 in dental clinic in Birjand city, $(n=270)$

Table 3 Association of knowledge on coronavirus disease 2019 with baseline characteristics

\begin{tabular}{|c|c|c|}
\hline \multirow[t]{2}{*}{ Overall score } & \multicolumn{2}{|l|}{ Mean \pm SD } \\
\hline & $36.7 \pm 3.5$ & \\
\hline \multicolumn{3}{|l|}{ Age } \\
\hline$<30$ & $32.75 \pm 7.9$ & 0.93 \\
\hline $30-39$ & $40.1 \pm 2.8$ & \\
\hline $40-49$ & $39.1 \pm 3.3$ & \\
\hline $50-59$ & $32.9 \pm 1.5$ & \\
\hline$\geq 60$ & $29.7 \pm 6.7$ & \\
\hline \multicolumn{3}{|l|}{ Gender } \\
\hline Male & $33.4 \pm 3.2$ & 0.21 \\
\hline Female & $35.8 \pm 3.6 .6$ & \\
\hline \multicolumn{3}{|l|}{ Residence } \\
\hline Rural & $37.1 \pm 8.1$ & 0.62 \\
\hline Urban & $42.7 \pm 4.6$ & \\
\hline \multicolumn{3}{|l|}{ Occupation } \\
\hline Employed & $38.1 \pm 2.9$ & 0.77 \\
\hline Self-employed & $31.9 \pm 3.7$ & \\
\hline Unemployed & $30.7 \pm 6.8$ & \\
\hline Student & $36.2 \pm 5.6$ & \\
\hline
\end{tabular}

healthcare services. Only 39 (14.5\%) of the study participants have reported the availability of COVID-19 screening services at the dentistry clinic.

\section{Patient satisfaction}

The overall patient satisfaction was $44.6 \%$ with a confidence interval (95\% CI 40.1-49.6). Whereas, $55.4 \%$ of study participants had dissatisfaction. Regarding patient satisfaction by educational level, more than half of the 48 (53.5\%) with primary school education were satisfied. More than two-fifth of the study participants 57 (47.1\%) who came from urban were satisfied (Table 4).

Frequency distribution of satisfaction level showed that 106 (39.3), 122 (45.2\%), and 42 (15.2\%) had high, medium, and low levels of satisfaction, respectively (Fig. 3).

\section{Discussion}

To the best of our knowledge, this is the first survey to evaluate the dental patients' knowledge and satisfaction regarding the implementation of health measures and protocols regarding COVID-19 in the dental environment along with treatment needs awareness during the pandemic time. All age categories in both men and women were included, with majority groups denoting a good socioeconomic background. Nearly, 65\% of the dental patients were found to have sufficient and good knowledge. This relatively high value implies the effectiveness of public information measures and advisories issued by government and health organizations during the COVID-19 outbreak. Recent researches showed good knowledge in infection control as a predictor of good practice $[16,17]$. Using sanitizer and alcohol for hand cleaning at the clinic entrance was significantly associated with patient satisfaction. This may be due to

Table 4 Distribution of satisfaction status by sociodemographic variables

\begin{tabular}{|c|c|c|}
\hline Variables & Satisfied, $n$ (\%) & Unsatisfied, $n(\%)$ \\
\hline \multicolumn{3}{|c|}{ Level of Patient satisfaction by educational status } \\
\hline Primary school & $48(53.5)$ & $42(46.5)$ \\
\hline Diploma & $52(24.6)$ & $160(75.4)$ \\
\hline Bachelor & $5(9.3)$ & $41(89.7)$ \\
\hline Above Bachelor & $8(12.6)$ & $53(87.4)$ \\
\hline \multicolumn{3}{|c|}{ Level of Patient satisfaction by monthly income } \\
\hline$\leq 30 \mathrm{mRial}$ & $54(68.9)$ & $142(31.1)$ \\
\hline 30mRial-50mRials & $24(22.9)$ & $48(70.1)$ \\
\hline 50mRial-70mRials & $38(37.7)$ & $62(62.3)$ \\
\hline$\geq 70 \mathrm{mRials}$ & $13(60.5)$ & $9(39.5)$ \\
\hline \multicolumn{3}{|c|}{ Level of Patient satisfaction by Residence area } \\
\hline Urban & $57(47.1)$ & $64(52.9)$ \\
\hline Rural & $79(53.2)$ & $70(47.1)$ \\
\hline
\end{tabular}




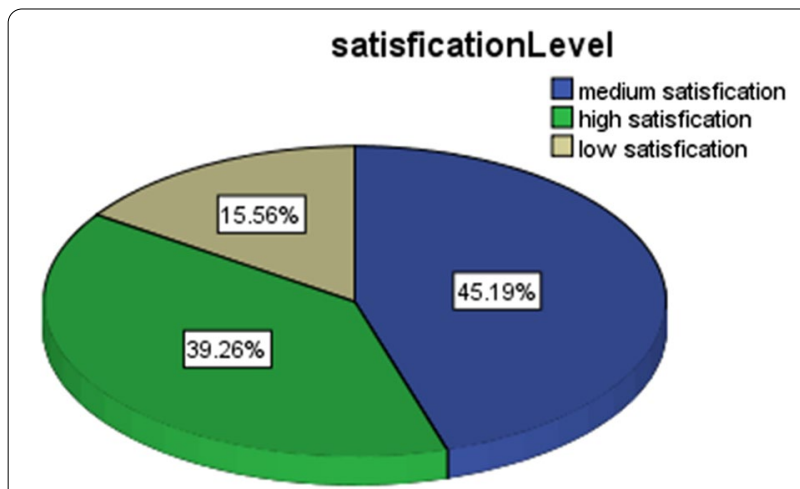

Fig. 3 Satisfaction level of patients from the implementation of health measures and protocols regarding COVID-19 in the dental environment $(n=270)$

COVID-19 infection prevention. As patients become aware of this strategy and unable to get it in the dental clinics may lead to dissatisfaction.

Patients who maintained and observed better social distancing at the registration and waiting places had significantly more satisfaction. This result is since WHO recognized as physical distancing is one of the COVID19 control strategies [18]. Hence, patients who found out and maintained social distancing increase their satisfaction. In return, overcrowding induces fear of being infected by COVID-19 that may increase patient dissatisfaction. Although, a substantial number of patients were unaware of ways to prevent the risk of COVID-19 infection transmission associated with dental treatment as well as imposed restrictions on dental procedures during this pandemic. Now, It is believed that respiratory droplets and contact transmission are the main sources of interpersonal transmission of COVID-19; but there are disputes regarding whether this virus can be spread through aerosols. A large number of droplets, splatter, and aerosols could be generated during dental procedures and the routine treatment plan with standard protective measures are not efficient enough to hamper the spread of COVID-19, particularly increasing in asymptomatic COVID-19 subjects or when they are in the incubation period or intend to conceal their infection $[19,20]$.

The relatively poor knowledge among dental patients about dental precautions proposes the requirement for awareness in these aspects. Participants in the range $30-50$ years had higher knowledge scores, maybe due to higher risk perception of the disease.

In India, the conscious actions taken by the central government have also contributed to decelerating the rate of spread of disease [21]. We should debunk myths and feed fear and misinformation by creating reliable sources of information at each level, within communities.
Most of the participants daresay that dental diseases are not serious as reported by over half of the population. Therefore, their knowledge needs to be enhanced in the same population. In addition, in association with the knowledge score about risk correlated with dental treatment, nearly, $70 \%$ stated that only emergency procedures as dental treatment should be done during the time of the pandemic. The governing institutions should monitor trends in local case counts and risk of community transmission, then after observing favorable situation can restart nonemergency procedures. On the other hand, SARS-CoV-2 transmission is highly correlated with Oral and maxillofacial surgery. To decrease the pressure on the healthcare system, it is essential to have an obvious concept for prioritizing procedures in surgeries [22]. In addition, due to transmission patterns can change, dental personnel should stay updated regarding the local transmission trends.

\section{Conclusions}

We attempted to provide a comprehensive inspection of the knowledge and satisfaction of dental patients toward health protocols COVID-19 during the time of the pandemic. The results indicate that most of the participants have sufficient knowledge and are positive in their perspective on the whole on prevailing the pandemic. Although, public knowledge is to be improved about the risk of virus transmission during dental treatment and also people should be encouraged to use virtual facilities, such as teledentistry, so that no dental emergencies are left untreated during the pandemic time.

The level of satisfaction was at a medium level for dental patients in the study area. Social distancing status, availability of alcohol, and sanitizer for hand cleaning at the entrance were factors associated with the satisfaction of patients. Dental clinics need to work on the COVID19 prevention and control strategy such as maintaining social distance, availing, alcohols, and sanitizers at the clinic entrance, also doing regular satisfaction evaluation, and monitoring feedback regularly.

\section{Abbreviations \\ COVID-19: Corona Virus Disease-2019; MPH: Master of Public Health; SPSS: Statistical Package for Social Science; WHO: World Health Organization.}

\section{Acknowledgements}

The authors acknowledge the Dentistry Clinical Research Development Center, Birjand University of Medical Sciences, Birjand, Iran for consulting, and dentistry clinic of University, from where data were collected, and study participants for their cooperation.

\section{Authors' contributions}

All authors made a significant contribution to the conception, study design, execution, and acquisition of data, analysis, and interpretation. All authors involved in drafting, revising, or critically reviewing the article; gave final approval of the version to be published; have agreed on the journal to which 
the article has been submitted; and agree to be accountable for all aspects of the work. All authors read and approved the final manuscript.

\section{Funding}

None.

\section{Availability of data and materials}

The data for this study area cannot be made publically available at present. It will be made available from the corresponding author on a reasonable request.

\section{Declarations}

\section{Ethics approval and consent to participate}

All procedures in this study were approved by the Ethical Committee of Birjand University of Medical Sciences, reference number: IR.BUMS. REC.1399.311. Informed consent was obtained from the study participants. The privacy and confidentiality of study participants were also be maintained strictly. Data collectors were informed about coding the questionnaire and not writing the study participants' names.

\section{Consent for publication}

Not applicable

\section{Competing interests}

The authors declare that they have no competing interests for this study.

\section{Author details}

'Dentistry Clinical Research Development Center, Birjand University of Medical Sciences, Birjand, Iran. ${ }^{2}$ Infectious Disease Research Center, Birjand University of Medical Sciences, Birjand, Iran.

\section{Received: 7 October 2021 Accepted: 30 December 2021}

Published online: 11 January 2022

\section{References}

1. Alharbi KG, Aldosari MN, Alhassan AM, Alshallal KA, Altamimi AM, Altulaihi BA. Patient satisfaction with virtual clinic during Coronavirus disease (COVID-19) pandemic in primary healthcare, Riyadh, Saudi Arabia. J Fam Community Med. 2021;28(1):48.

2. Osman F. Statistical ambiguities in epidemics of coronavirus disease 2019 (COVID-19). Acta Med Iran. 2020. https://doi.org/10.18502/acta.v58i3. 3780.

3. Rajgor DD, Lee MH, Archuleta S, Bagdasarian N, Quek SC. The many estimates of the COVID-19 case fatality rate. Lancet Infect Dis. 2020;20(7):776-7.

4. Osmani F. Problems with the accurate reporting of COVID-19 statistics in Iran. Gastroenterol Hepatol Bed Bench. 2020;13(4):275.

5. Peng X, Xu X, Li Y, Cheng L, Zhou X, Ren B. Transmission routes of 2019nCoV and controls in dental practice. Int J Oral Sci. 2020;12(1):1-6.

6. Mohammadi-Moghaddam M, Zebarjadi M, Osmani F. Knowledge, attitude, and practice of dentists regarding periodontal tissue health in Birjand, Northeast Iran. Private Pract. 2021;13:12-4.

7. Parvaie P, Ebrahimian Baghan S, Zardast M, Sharifzadeh G, Osmani F. Prevalence of anti-herpes simplex virus type 1 among dental students of Birjand University of Medical Sciences, Iran, 2017-2018. Journal of Birjand University of Medical Sciences.

8. Li B, Li X, Wang Y, Han Y, Wang Y, Wang C, et al. Diagnostic value and key features of computed tomography in Coronavirus Disease 2019. Emerg Microb Infect. 2020;9(1):787-93.

9. Kamate SK, Sharma S, Thakar S, Srivastava D, Sengupta K, Hadi AJ, et al. Assessing knowledge, attitudes and practices of dental practitioners regarding the COVID-19 pandemic: a multinational study. Dent Med Probl. 2020;57(1):11-7.

10. Osmani F, Azarkar G. Fitting logistic regression models to assess vitamin D deficiency with clinical parameters in chronic hepatitis B patients. Infect Dis Model. 2021;6:612-7.
11. Ferdous MZ, Islam MS, Sikder MT, Mosaddek ASM, Zegarra-Valdivia J, Gozal D. Knowledge, attitude, and practice regarding COVID-19 outbreak in Bangladesh: an online-based cross-sectional study. PLoS ONE. 2020;15(10):e0239254.

12. Hocking A, Laurence C, Lorimer M. Patients' knowledge of their chronic disease: the influence of socio-demographic characteristics. Aust Fam Phys. 2013;42(6):411-6.

13. Osmani F, Hajizadeh E, Rasekhi A, Akbari ME. Prognostic factors associated with locoronal relapses, metastatic relapses, and death among women with breast cancer. Population-based cohort study. Breast. 2019;48:82-8.

14. Deriba BS, Geleta TA, Beyane RS, Mohammed A, Tesema M, Jemal K. Patient satisfaction and associated factors during COVID-19 pandemic in North Shoa Health Care Facilities. Patient Prefer Adherence. 2020;14:1923.

15. Ahmadi H, Ebrahimi A, Ghorbani F. The impact of COVID-19 pandemic on dental practice in Iran: a questionnaire-based report. BMC Oral Health. 2020;20(1):1-9.

16. Zegarra-Valdivia J, Vilca BNC, Guerrero RJA. Knowledge, perception and attitudes in Regard to COVID-19 Pandemic in Peruvian Population. 2020.

17. Volgenant CM, Persoon IF, de Ruijter RA, de Soet J. Infection control in dental health care during and after the SARS-CoV-2 outbreak. Oral Dis. 2021;27:674-83.

18. Farooq I, Ali S. COVID-19 outbreak and its monetary implications for dental practices, hospitals and healthcare workers. Postgrad Med J. 2020:96(1142):791-2.

19. Gillman-Wells CC, Sankar TK, Vadodaria S. COVID-19 reducing the risks: telemedicine is the new norm for surgical consultations and communications. Aesthetic Plast Surg. 2021;45(1):343-8.

20. Meng L, Hua F, Bian Z. Coronavirus disease 2019 (COVID-19): emerging and future challenges for dental and oral medicine. J Dent Res. 2020;99(5):481-7.

21. Singh $M$, Singh $K$, Puri M, Anandani $C$, Singh $H$, Sharma A. Knowledge and perception towards Zika outbreak in a dental institute. Dentistry. 2017. https://doi.org/10.4172/2161-1122.1000420.

22. Zimmermann M, Nkenke E. Approaches to the management of patients in oral and maxillofacial surgery during COVID-19 pandemic. J CranioMaxillofacial Surg. 2020;48(5):521-6.

\section{Publisher's Note}

Springer Nature remains neutral with regard to jurisdictional claims in published maps and institutional affiliations.

Ready to submit your research? Choose BMC and benefit from:

- fast, convenient online submission

- thorough peer review by experienced researchers in your field

- rapid publication on acceptance

- support for research data, including large and complex data types

- gold Open Access which fosters wider collaboration and increased citations

- maximum visibility for your research: over $100 \mathrm{M}$ website views per year

At BMC, research is always in progress.

Learn more biomedcentral.com/submissions 